\title{
The impact of age, sex, disc height loss and T1 slope on the upper and lower cervical lordosis: a large-scale radiologic study
}

\author{
Youping Tao ${ }^{1} \cdot$ Fabio Galbusera ${ }^{2} \cdot$ Frank Niemeyer $^{1} \cdot$ René Jonas $^{1} \cdot$ Dino Samartzis $^{3,4} \cdot$ Daniel Vogele $^{5}$. \\ Hans-Joachim Wilke' ${ }^{1}$ (1)
}

Received: 9 March 2021 / Accepted: 14 July 2021 / Published online: 30 July 2021

(c) The Author(s) 2021

\begin{abstract}
Purpose To clarify the relative influence of age, sex, disc height loss and T1 slope on upper (Occiput-C2) and lower cervical lordosis (C2-C7).

Methods Standing lateral cervical radiographs of 865 adult subjects were evaluated. The presence and severity of disc height loss from $\mathrm{C} 2 / \mathrm{C} 3$ to $\mathrm{C} 6 / \mathrm{C} 7$ (a total of 4325 discs) were assessed using a validated grading system. The total disc height loss score for each subject was calculated as the sum of the score of each disc space. Sagittal radiographic parameters included: occipital slope, occiput-C2 (Oc-C2) lordosis, C2-C7 lordosis and T1 slope. Multivariable regression analyses were performed to examine the relative influence of the multiple factors on upper and lower cervical lordosis.

Results This study included 360 males and 505 females, with a mean age of 40.2 \pm 16.0 years (range, 20-95 years). Linear multivariate regression analyses showed that greater age, male sex, greater T1 slope were each found to be significantly and independently associated with greater $\mathrm{C} 2-\mathrm{C} 7$ lordosis, whereas total disc height loss score was negatively associated with C2-C7 lordosis. T1 slope had the most independent influence on C2-C7 lordosis among these factors. Age, sex and disc height loss were not independently associated with Oc-C2 lordosis.

Conclusions Results from our large-scale radiologic analysis may enhance the understanding of the factors that affect cervical lordosis, indicating that age, sex, disc height loss and T1 slope were each independently associated with C2-C7 lordosis. However, age, sex and disc height loss were not independently associated with upper cervical lordosis.
\end{abstract}

Keywords Cervical spine $\cdot$ Age-related $\cdot$ Sex $\cdot$ T1 slope

Hans-Joachim Wilke

hans-joachim.wilke@uni-ulm.de

1 Institute of Orthopaedic Research and Biomechanics, Trauma Research Center Ulm, Ulm University, Helmholtzstrasse 14, 89081 Ulm, Germany

2 IRCCS Istituto Ortopedico Galeazzi, Milan, Italy

3 Department of Orthopaedic Surgery, Rush University Medical Center and Rush Graduate College, Chicago, IL, USA

4 International Spine Research and Innovation Initiative, Rush University Medical Center, Chicago, IL, USA

5 Department of Diagnostic and Interventional Radiology, University Hospital Ulm, Ulm, Germany

\section{Introduction}

Cervical lordosis is one of the critical parameters of cervical and global sagittal alignment $[1,2]$. Although the functional and clinical importance of cervical lordosis have been widely investigated and highlighted, the factors affecting the lordotic curve of cervical spine have not been explored in detail. The cervical lordosis is influenced by several factors. Recently, numerous studies extensively investigated the impact of age and sex on the cervical lordosis, but the published data showed conflicting findings. For example, prior studies documented that cervical lordosis (i.e. C2-C7 lordotic angle) increased with ageing and there was no difference between males and females [3, 4]. On the contrary, a meta-analysis showed that the cervical lordosis was higher in males than in females and there was no significant relationship between lordosis and age [5]. 
Age-related change of cervical intervertebral disc height loss is one of the most clinically relevant degenerative phenotypes which can be extracted from lateral plain radiographs $[6,7]$. For example, disc height loss has been applied widely as one of the criteria for the radiographic diagnosis of adjacent segment pathology after anterior cervical surgeries for degenerative cervical diseases [8]. It has been previously reported that loss of cervical lordosis was associated with loss of disc space height [7,9]. Despite this, the independent influence of the severity of disc height loss on cervical lordosis is still not extensively documented in any large-scale radiographic study after adjustment for age $[7,10]$.

T1 slope has recently emerged as one of the critical determinants of cervical lordosis [11], and it has been documented that the greater is T1 slope, the larger is the cervical lordosis needed to maintain horizontal gaze. Very recent studies showed that $\mathrm{T} 1$ slope itself was significantly influenced by age and sex [3, 4]. Additionally, C2-C7 lordosis is interconnected with other occipitocervical alignment parameters, such as occipital slope and occiput-C2 angle [3,11].

Thus far, the relative influence of age, sex, the extent of disc height loss and $\mathrm{T} 1$ slope on upper (occiput-C2) and lower cervical lordosis ( $\mathrm{C} 2-\mathrm{C} 7$ angles) remains unknown. This knowledge gap exists since the majority of the previous investigations included a limited sample size, a narrowage range or did not analyse these common factors together within one study sample. In addition, the analyses were fairly limited and did not account for the potential confounding or interaction effects, making interpretation of the findings a challenge and a continued point of discussion.

A fundamental understanding of the factors that affect cervical lordosis is critical to future studies involving cervical lordosis. In this paper, we aim at specifically clarifying the relative influence of age, sex, disc height loss and T1 slope on the upper and lower cervical lordosis by means of a retrospective analysis of the lateral radiographs of 865 adult subjects.

\section{Materials and methods}

\section{Study sample}

A retrospective radiographic study was performed, following approval by the local ethical committee board. In this study, neutral lateral cervical radiographs of 865 adult subjects from a single university hospital between 2016 and 2019 were analysed. The dataset was similarly used in a previous study [6]. The standing lateral plain radiographs of the cervical spine were taken routinely with the subject in a comfortable upright position and the arms positioned at the side of the body, and with horizontal gaze. In this work, exclusion criteria were: (1) subjects younger than 20 years of age; (2) a history of previous surgery; (3) congenital abnormalities, fractures, tumour, infection or inflammatory arthritis; (4) invisible superior endplate of T1 vertebral body; and (5) incorrect head position as previously described $[12,13]$.

\section{Sagittal radiographic measurements}

Occipital slope is defined as the angle between the McRae line and the horizontal line; occipital slope angles were considered positive when the angles opened above the horizontal line $[3,14]$. Occiput-C2 lordosis $(\mathrm{Oc}-\mathrm{C} 2)$ is defined as the angle between the McRae line and the inferior endplate of $\mathrm{C} 2[3,11]$. C2-C7 lordosis is defined as the angle between the posterior body tangents on $\mathrm{C} 2$ and $\mathrm{C} 7$ [15]. According to previous studies $[3,11]$, cervical lordosis was divided into upper lordosis (Oc-C2 angle) and lower lordosis (C2-C7 angle). Lordotic angles are positive, and kyphotic angles are negative in this study. T1 sagittal slope is defined as the angle between the upper endplate of the $\mathrm{T} 1$ vertebral body and the horizontal line [11]. T1 slope angles were considered positive when the angles opened below the horizontal line. Examples of measurements of occipital slope, Oc-C2 and $\mathrm{C} 2-\mathrm{C} 7$ lordosis and $\mathrm{T} 1$ slope are all shown in Fig. 1.

\section{Scoring for radiographic disc height loss}

The presence and severity of intervertebral disc space height loss from $\mathrm{C} 2 / \mathrm{C} 3$ to $\mathrm{C} 6 / \mathrm{C} 7$ (a total of 4325 intervertebral discs) in this study were scored according to

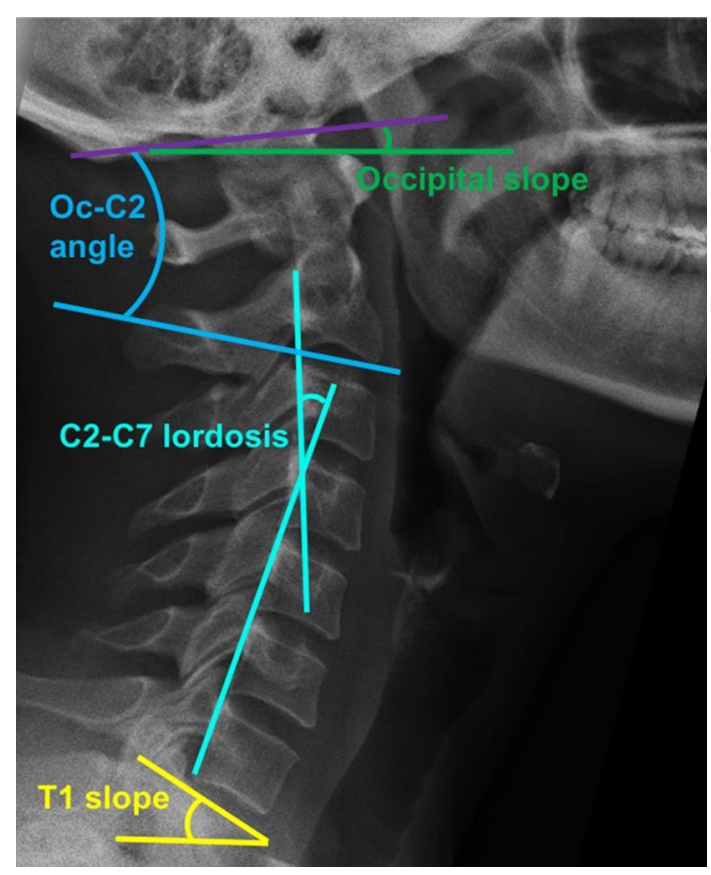

Fig. 1 Examples of measurements of occipital slope, Oc-C2 and C2C7 lordosis and T1 slope 
Kettler's grading scheme [16]. Briefly, disc height loss was scored for each disc space with respect to the normative values in the population: "normal" ( 0 points $)$, if there was no height loss; "minimal" (1 point), if less than $30 \%$ decrease in disc height; "moderate" ( 2 points), if the decrease in disc height was more than $33 \%$ but less than $66 \%$; "severe" (3 points), if the decrease in disc height was more than $66 \%$. The total disc height loss score for each patient was calculated as the sum of the score of each disc space and possibly ranged from 0 to 15 .

The sagittal radiographic evaluation was performed using with Surgimap software (Version 2.3.2.1, New York, NY). All the radiographs were evaluated by a spinal surgeon, and excellent reproducibility was noted for the cervical sagittal radiographic parameters (range of intraclass correlation coefficient from 0.91 to 0.97 ) and for the radiographic disc height loss $(0.87$, by weighted kappa statistic) [17].

\section{Statistical analysis}

Descriptive analysis was performed for radiographic parameters. Mann-Whitney U test was used to compare the differences of continuous variables between males and females. Spearman's rank correlation coefficient $(r)$ was performed to investigate the relationship among the radiographic parameters and age. The strength of the correlation was classified as negligible $(0.00-0.10)$, weak (0.10-0.39), moderate (0.40-0.69), strong (0.70-0.89) and very strong $(0.90-1.00)$ [18].

Stepwise multivariate linear regression analysis was carried out to examine the relative influence of age, sex, disc height loss and $\mathrm{T} 1$ slope on the upper and lower cervical lordosis (e.g. Oc-C2 and C2-C7 lordosis angles). The values of $p<0.05$ were considered to indicate statistical significance. All statistical analyses were performed using IBM SPSS software version 27.0.

\section{Results}

The current study included 360 males and 505 females, with a mean age of $40.2 \pm 16.0$ years (range, 20-95 years). Table 1 illustrates the distribution of subjects in this study.

\section{Sagittal radiographic parameters}

Overall, in this cohort, the mean occipital slope was $10.2 \pm 6.4^{\circ}$ (range: $-5.9-32.0^{\circ}$ ). The mean Oc-C2 lordosis was $23.4 \pm 8.1^{\circ}$ (range: $2.3-47.6^{\circ}$ ). The mean $\mathrm{C} 2-\mathrm{C} 7$ lordosis was $15.2 \pm 12.3^{\circ}$ (range: $-17.1-49.3^{\circ}$ ), and the mean $\mathrm{T} 1$ slope was $25.6 \pm 9.2^{\circ}$ (range: $0.4-49.2^{\circ}$ ). The results of these sagittal parameters were generally consistent with previously published data in the literature $[3,4,11,19]$.

\section{Influence of sex and age on sagittal parameters and disc height loss}

In general, males had higher $\mathrm{C} 2-\mathrm{C} 7$ lordosis than females, whereas the mean Oc-C2 lordosis was larger in females than that in males ( $p<0.0001$, respectively). In addition, males had larger T1 slope than females $(p<0.0001)$, whereas the mean occipital slope was greater in females than that in males $(p=0.012)$. The detailed sex-related differences in the sagittal parameters at each age group are presented in Fig. 2.

Among the all subjects, there were weak but significant positive correlations between age and $\mathrm{C} 2-\mathrm{C} 7$ lordosis $(r=0.247, p<0.0001)$, occipital slope $(r=0.143$, $p<0.0001)$ and T1 slope $(r=0.187, p<0.0001)$, but no significant correlation between Oc-C2 lordosis with age was found $(p=0.765)$. The detailed results of correlations between age and the sagittal parameters of cervical spine in males and females are presented in Fig. 3.

In this cohort, $42.8 \%$ (370/865) of all individuals showed radiographic disc height loss. The moderate and severe disc height loss were more commonly found at C5/C6 and C6/ C7 disc levels (Fig. 4). The mean total disc height loss score was $1.3 \pm 2.0$ (range: $0-11$ ), and there was no significant
Table 1 The distribution of subjects in each age group $(N=865)$

\begin{tabular}{llll}
\hline Age group & Number of males (\%) & Number of females (\%) & $\begin{array}{l}\text { Number of } \\
\text { total subjects } \\
(\%)\end{array}$ \\
\hline $20-29$ years & $127(35.3 \%)$ & $163(32.3 \%)$ & $290(33.5 \%)$ \\
$30-39$ years & $87(24.2 \%)$ & $100(19.8 \%)$ & $187(21.6 \%)$ \\
$40-49$ years & $65(18.0 \%)$ & $73(14.5 \%)$ & $138(16.0 \%)$ \\
$50-59$ years & $46(12.8 \%)$ & $94(18.6 \%)$ & $140(16.2 \%)$ \\
$60-69$ years & $20(5.5 \%)$ & $43(8.5 \%)$ & $63(7.3 \%)$ \\
$\geq 70$ years & $15(4.2 \%)$ & $32(6.3 \%)$ & $47(5.4 \%)$ \\
$20-95$ years (Total) & $360(100 \%)$ & $505(100 \%)$ & $865(100 \%)$ \\
\hline
\end{tabular}



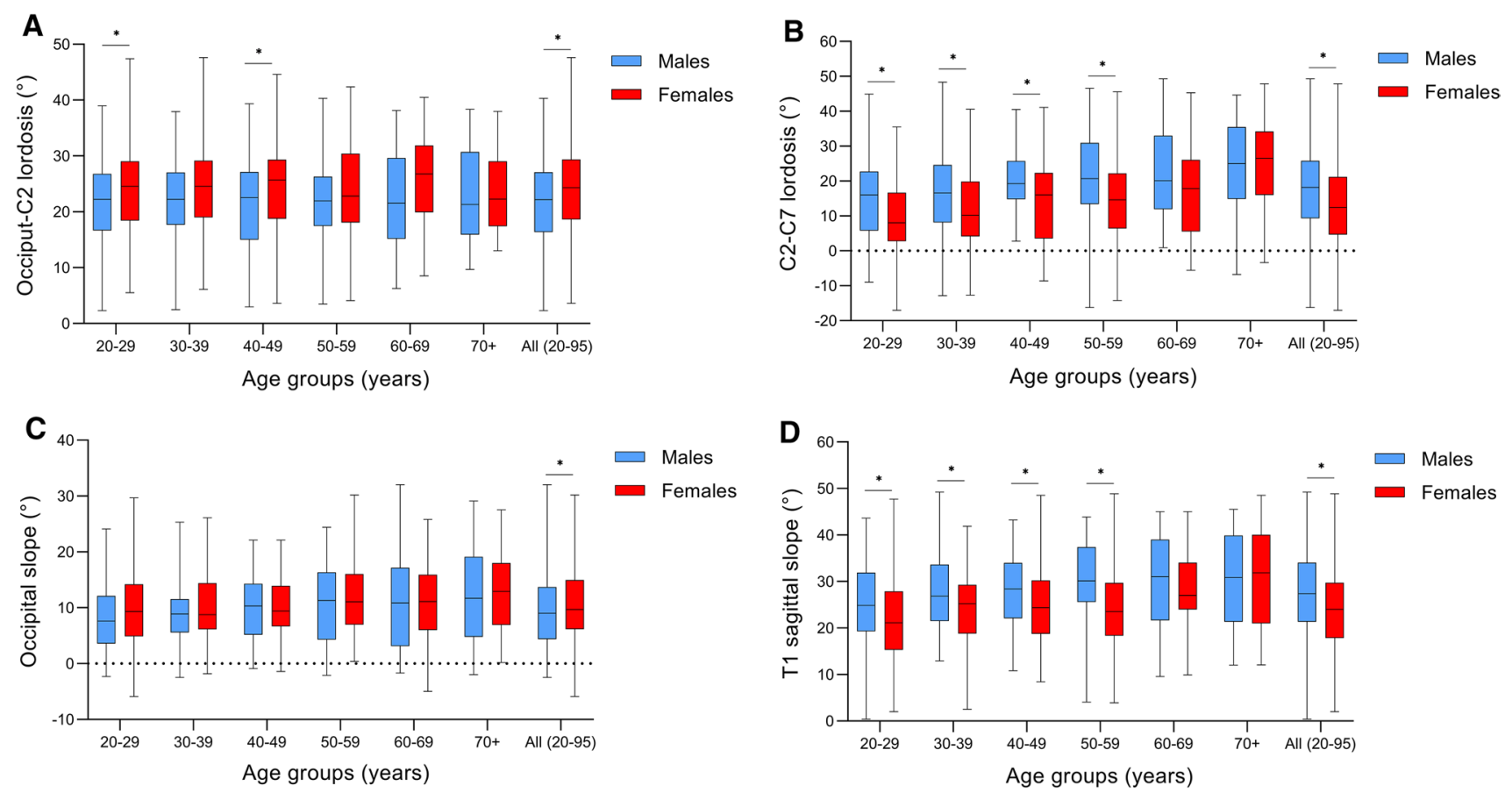

Fig. 2 Box plots showing the median value and range of sagittal parameters by age and sex (*indicates significant difference between males and females, $p<0.05$ )

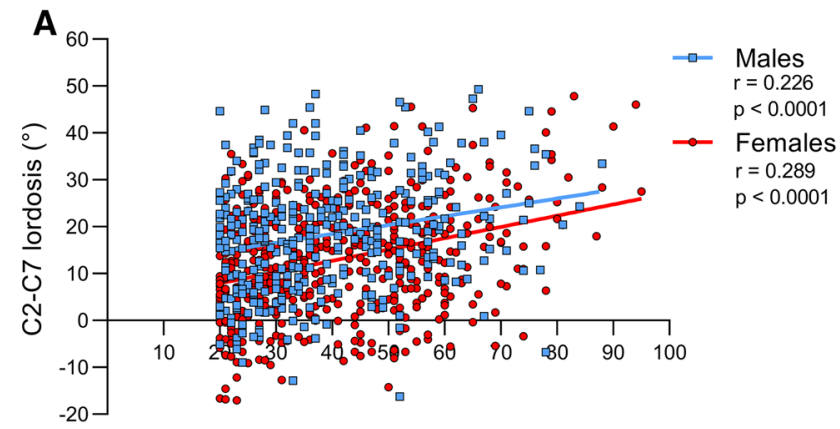

Age (years)
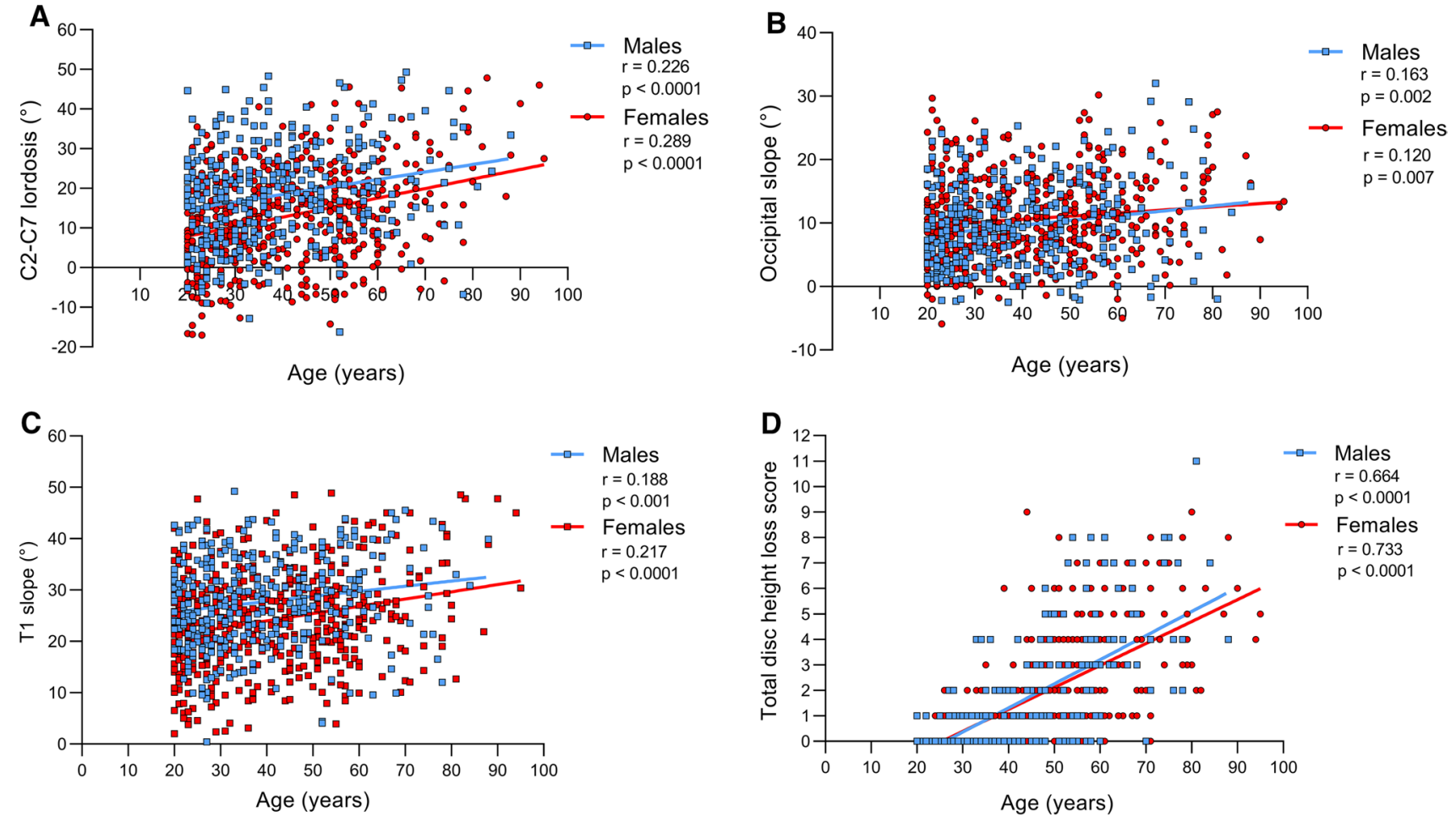

Fig. 3 Correlation between age and sagittal parameters and total disc height loss in males and females 
Fig. 4 Prevalence and distribution of degree of disc height loss at each level

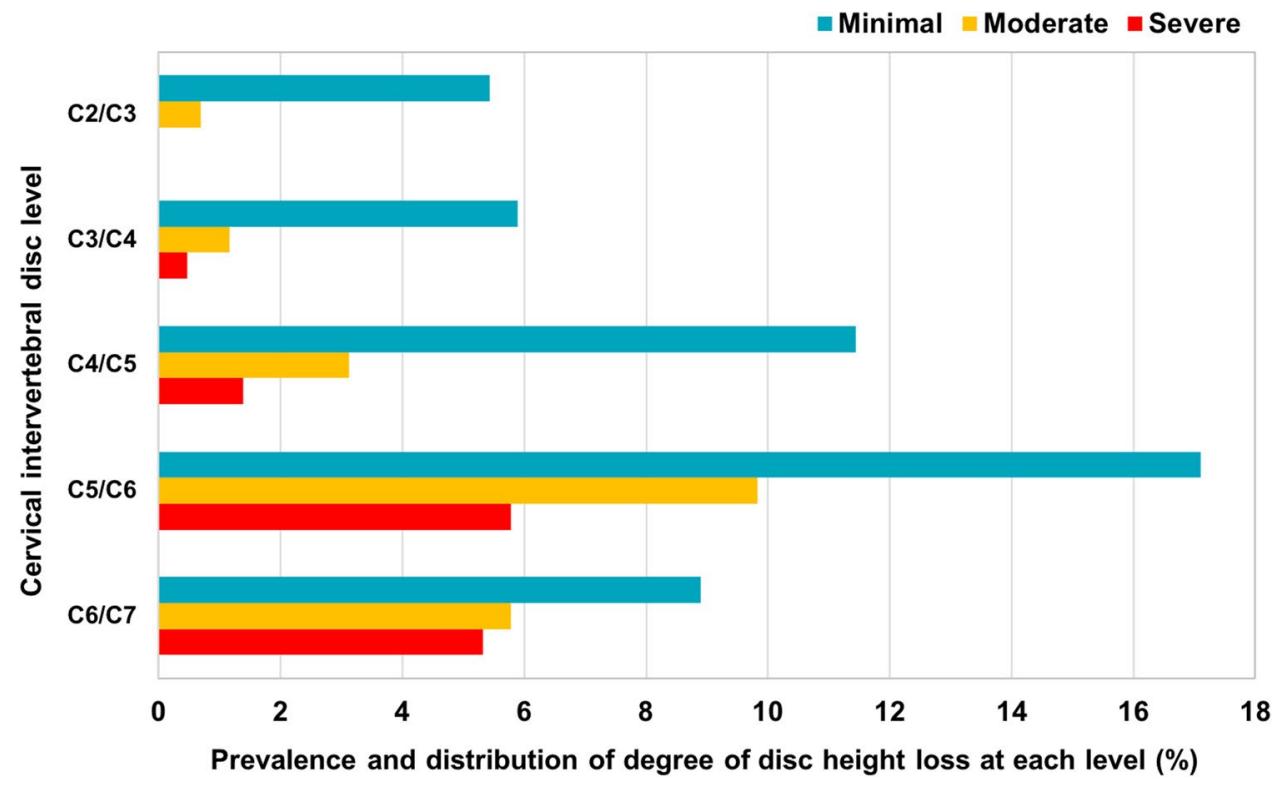

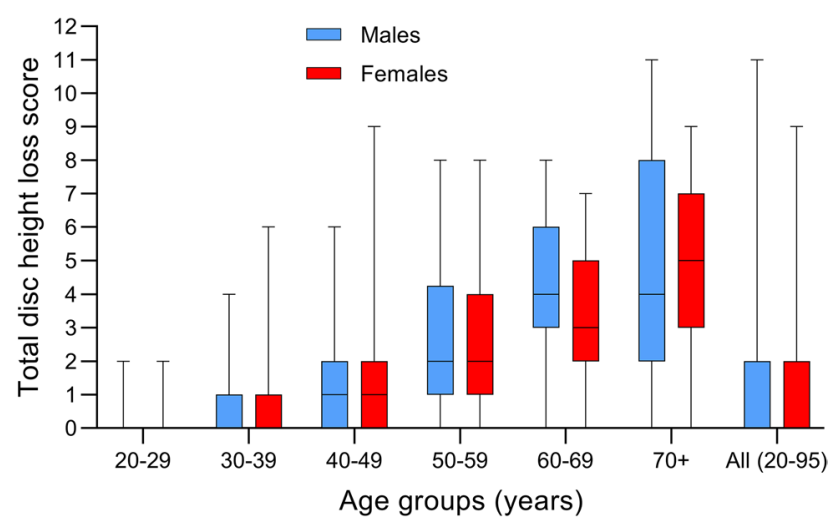

Fig. 5 Box plots showing the median value and range of total disc height loss by age and sex

difference between males and females in terms of the total disc height loss score $(p=0.067)$ (Fig. 5). There was strong statistical correlation between age and total disc height loss score $(r=0.709, p<0.0001)$ among all subjects. Furthermore, there was strong positive correlation between age and total disc height loss score in females and of moderate correlation in males (Fig. 3).

\section{Correlations among the cervical sagittal parameters}

Among all subjects, there were weak but significant positive correlations between occipital slope and upper $(r=0.284, p<0.0001)$ and lower cervical lordosis $(r=0.151, p<0.0001)$. Moderate negative correlation between Oc-C2 and C2-C7 lordosis was found ( $r=0.400$, $p<0.0001)$. There was significant moderate positive correlation between $\mathrm{T} 1$ slope and $\mathrm{C} 2-\mathrm{C} 7$ lordosis $(r=0.633, p$
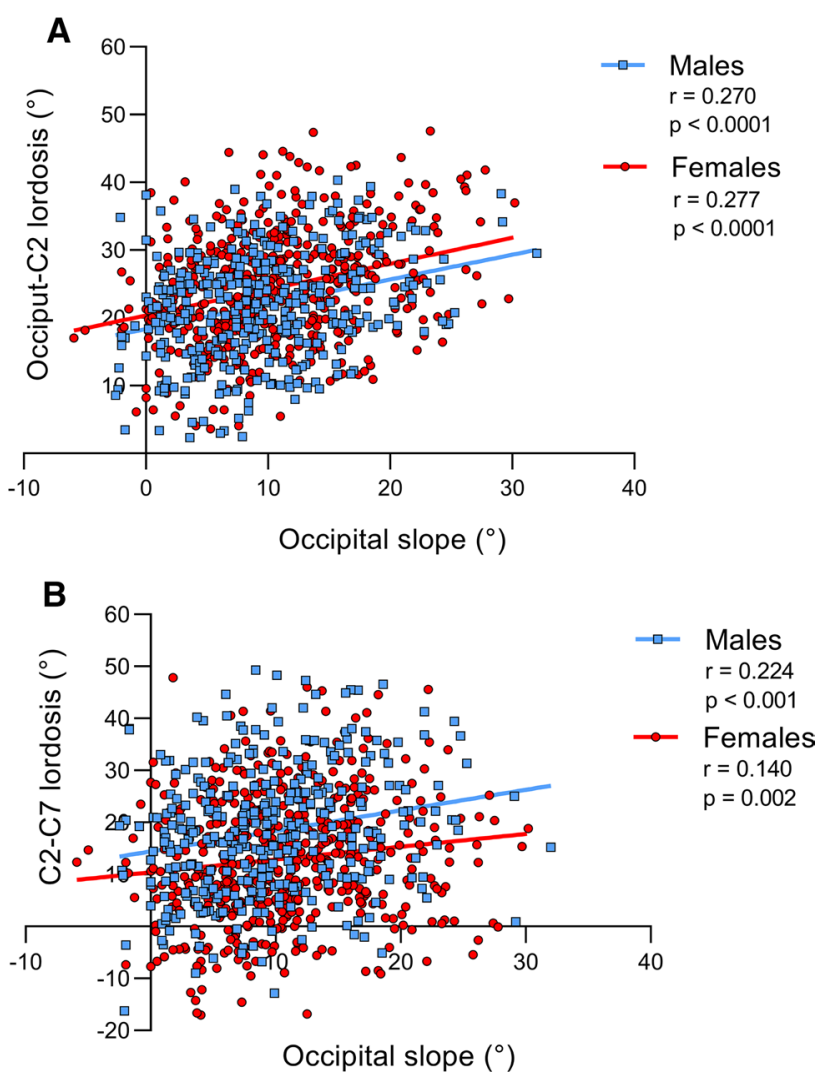

Fig. 6 Correlation between occipital slope and upper and lower cervical lordosis in males and females

$<0.0001)$, whereas no direct correlation between T1 slope and Oc-C2 lordosis was noted $(p=0.546)$. The detailed correlations among the sagittal parameters in males and females are presented in Figs. 6, 7, 8. These results of 


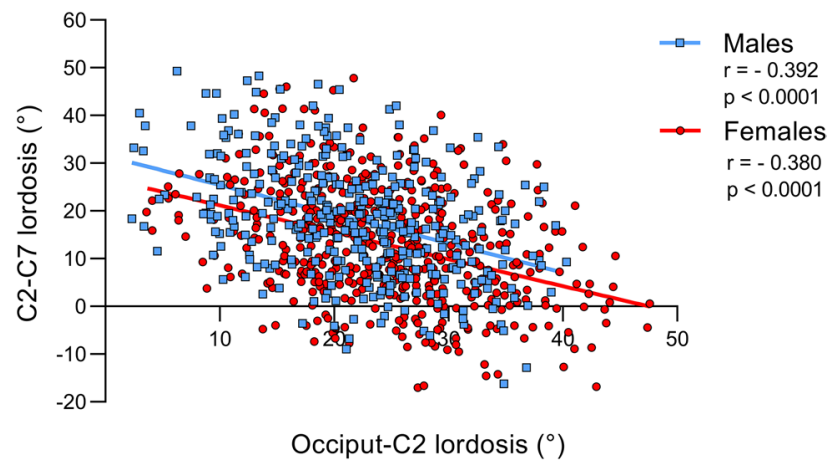

Fig. 7 Correlation between upper and lower cervical lordosis in males and females

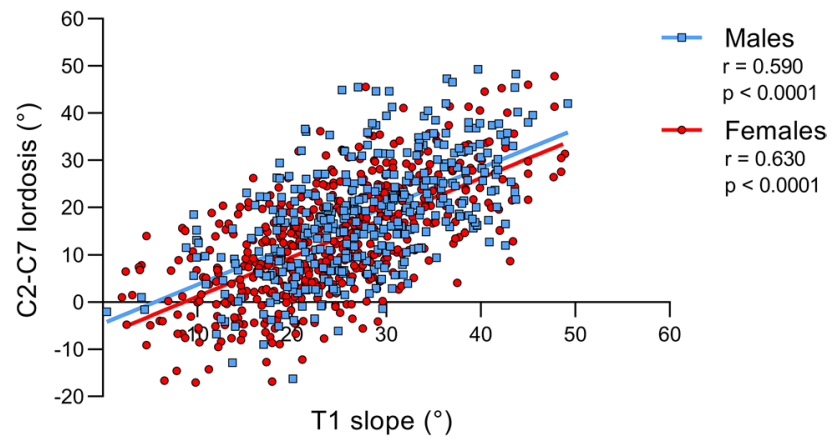

Fig. 8 Correlation between $\mathrm{T} 1$ slope and $\mathrm{C} 2-\mathrm{C} 7$ lordosis in males and females

Table 2 Results of multivariate linear regression analyses $(N=865)$

\begin{tabular}{|c|c|c|c|c|}
\hline & $\mathrm{B}$ & SE & $\beta$ & $p$ value \\
\hline \multicolumn{5}{|c|}{$\begin{array}{l}\text { Factors associated with upper lordosis (Oc-C2 lordosis angle as } \\
\text { dependent variable) }\end{array}$} \\
\hline \multicolumn{5}{|l|}{ Independent variables } \\
\hline $\mathrm{C} 2-\mathrm{C} 7$ lordosis & -0.648 & 0.021 & -0.979 & $<0.0001$ \\
\hline Occipital slope & 0.795 & 0.031 & 0.629 & $<0.0001$ \\
\hline T1 slope & 0.672 & 0.028 & 0.757 & $<0.0001$ \\
\hline (Constant) & 7.875 & 0.746 & & \\
\hline \multicolumn{5}{|c|}{$R=0.763, R^{2}=0.582$, adjusted $R^{2}=0.580 ;$ Durbin-Wasson $=2.082$} \\
\hline \multicolumn{5}{|c|}{$\begin{array}{l}\text { Factors associated with lower lordosis (C2-C7 lordosis angle as } \\
\text { dependent variable) }\end{array}$} \\
\hline \multicolumn{5}{|l|}{ Independent variables } \\
\hline T1 slope & 0.959 & 0.024 & 0.715 & $<0.0001$ \\
\hline Occiput-C2 & -0.807 & 0.026 & -0.534 & $<0.0001$ \\
\hline Occipital slope & 0.899 & 0.035 & 0.470 & $<0.0001$ \\
\hline Age (years) & 0.087 & 0.019 & 0.114 & $<0.0001$ \\
\hline Total disc height loss score & -0.418 & 0.141 & -0.069 & 0.003 \\
\hline Sex & 0.920 & 0.421 & 0.037 & $\mathbf{0 . 0 2 9}$ \\
\hline (Constant) & -3.035 & 1.011 & & \\
\hline \multicolumn{5}{|c|}{$R=0.879, R^{2}=0.773$, adjusted $R^{2}=0.771 ;$ Durbin-Wasson $=2.044$} \\
\hline
\end{tabular}

$B$ Unstandardized B; SE Coefficients std. error; $\beta$ Standardized coefficients beta; Bolded values indicate statistical significance at $p<0.05$ correlations among the cervical sagittal parameters were similar to previous studies [3, 11].

\section{Results of multivariate analysis}

As presented in Table 2, T1 slope affected Oc-C2 angle, whereas no independent association of age, sex and total disc height loss score with upper cervical lordosis. The combined influence explained $58.2 \%$ of the variability in the Oc-C2 lordosis $\left(R=0.763, R^{2}=0.582\right)$.

When age, sex, total disc height loss score, T1 slope and occipitocervical parameters were taken together, multivariate analysis showed that greater age, male sex, greater T1 slope and occipital slope were significantly associated with greater $\mathrm{C} 2-\mathrm{C} 7$ lordosis, whereas total disc height loss score and $\mathrm{Oc}-\mathrm{C} 2$ angle were negatively associated with $\mathrm{C} 2-\mathrm{C} 7$ lordosis (Table 2). Moreover, T1 slope had a greater influence (larger $\beta$ coefficient) on $\mathrm{C} 2-\mathrm{C} 7$ lordosis than any of the other independent variables in the regression model. The combined influence explained $77.3 \%$ of the variability in the C2-C7 lordosis $\left(R=0.879, R^{2}=0.773\right)$.

\section{Discussion}

To our knowledge, this is the first study that specially clarifies the relative influences of age, sex, the extent of disc height loss and $\mathrm{T} 1$ slope on the upper and lower cervical lordosis using multivariate analyses with the largest cervical lateral radiographs currently available. Importantly, among several independent variables studied in our study, we found that $\mathrm{T} 1$ slope had the greatest independent influence on C2-C7 lordosis. In addition, age, sex and disc height loss were not independently associated with upper lordosis (Table 2).

The current study showed an average occipital slope of $10.2 \pm 6.4^{\circ}$, Oc-C2 of $23.4 \pm 8.1^{\circ}, \mathrm{C} 2-\mathrm{C} 7$ lordosis of $15.2 \pm 12.3^{\circ}$ and $\mathrm{T} 1$ slope of $25.6 \pm 9.2^{\circ}$. Our results of these sagittal radiographic parameters are generally in good agreement with previous data. For example, in a study with full-body radiographs of 115 adult volunteers, Iyer et al. [3] reported the mean values of $9.4 \pm 8.5^{\circ}$ for the occipital slope, $-27.4 \pm 9.4^{\circ}$ for $\mathrm{Oc}-\mathrm{C} 2,-12.2 \pm 13.6^{\circ}$ for $\mathrm{C} 2-\mathrm{C} 7$ lordosis and $26.1 \pm 9^{\circ}$ for $\mathrm{T} 1$ slope. Yokoyama et al. [19] investigated the lateral whole-spine standing radiographs of 220 asymptomatic individuals aged 20-95 years, and they reported the mean C2-C7 lordosis angle (with the posterior tangent technique) of $13.9 \pm 14.2^{\circ}$ and $\mathrm{T} 1$ slope of $24.6 \pm 7.5^{\circ}$.

We found that $\mathrm{C} 2-\mathrm{C} 7$ lordosis significantly increased with age. To date, the influence of age on cervical lordosis is still being debated. For instance, Yokoyama et al. [19] reported that age was significantly associated with $\mathrm{C} 2-\mathrm{C} 7$ lordosis, which was consistent with our study. However, 
a meta-analysis showed no evidence that $\mathrm{C} 2-\mathrm{C} 7$ lordosis was influenced by age [5]. In addition, we found that there was no significant impact of age on Oc-C2 lordosis; similar results were reported in previous investigations $[3,11]$. Consequently, our results from multivariate analyses add to the evidence that the lower cervical lordosis was affected by age. The increase in cervical lordosis observed with ageing likely reflects the progressive loss of sagittal balance due to degeneration and osteoporosis in the thoracolumbar spine $[2,20]$, which was, however, not documented in this paper which did not include radiographs of the full trunk [2, 3, 14].

Our results showed that lower cervical lordosis (C2-C7 lordosis) was significantly and independently associated with sex after adjustment for various factors. Currently, the sex-related difference in cervical lordosis also remains controversial. A recent meta-analysis reported that males had greater $\mathrm{C} 2-\mathrm{C} 7$ lordosis than females $(\mathrm{C} 2-\mathrm{C} 7$ angles with posterior tangent method) [5], which was consistent with our data. Additionally, in this study, we found that sex was not associated with Oc-C2 lordosis, as previously described [3, 11]. Collectively, these findings suggested that the influence of sex on the lower cervical lordosis should not be ignored in the future studies [12,21].

In this study, as expected, we found that radiographic disc height loss was most severely seen at C5/C6 followed by $\mathrm{C} 6 / \mathrm{C} 7$, and the total score for disc height loss significantly increased with age. These results were in good agreement with previous study [7]. In fact, very few large-scale radiological studies directly investigated the independent influence of the extent of disc height loss on upper and lower cervical lordosis after adjusting age and other cervical sagittal parameters. Our multivariate analysis demonstrated that with an increasing severity of disc height loss was significantly associated with the reduction in $\mathrm{C} 2-\mathrm{C} 7$ lordosis. This finding agreed with previous studies [7, 9]. Interestingly, we noted that the extent of disc height loss was not independently associated with Oc-C2 lordosis. Altogether, our results not only confirmed that the close association between cervical lordosis and the extent of disc height loss, but also suggested that age-related disc space collapse was independently associated with loss of cervical lordosis in the $\mathrm{C} 2-\mathrm{C} 7$ region but not in the Oc-C2 segment.

Our results showed that males had larger T1 slope than females, and T1 slope itself significantly increased with ageing, which were consistent with recent radiographic studies $[3,4]$. In our study, results from correlation analysis showed that $\mathrm{T} 1$ slope was moderately related to $\mathrm{C} 2-\mathrm{C} 7$ lordosis; $\mathrm{C} 2-\mathrm{C} 7$ lordosis was inversely related with Oc-C2 lordosis, whereas there was no direct relation between $\mathrm{T} 1$ slope and Oc-C2, skipping the $\mathrm{C} 2-\mathrm{C} 7$ lordosis. Similar results were presented by Lee et al. [11]. Of importance, in our study, multivariate analysis showed that not only $\mathrm{T} 1$ slope was significantly associated with $\mathrm{C} 2-\mathrm{C} 7$ lordosis, but it also had the greatest influence on C2-C7 lordosis (Table 2). These results indicated the reciprocal compensatory mechanism of cervical sagittal alignment to maintain horizontal gaze. Taken together, our large radiographic analyses further confirmed and emphasized the importance of $\mathrm{T} 1$ slope in determining sagittal balance of the cervical spine [11, 14].

This study has several limitations. First, since cross-sectional nature of the present study, theoretically, longitudinal studies may provide more detail information on the nature course of ageing in the cervical lordosis profiles. Second, the present study has a retrospective design and clinical data such as patient symptoms were not available; therefore, the association of the radiographic parameters with pain and disability could not be investigated. Third, our study did not allow us to determine the causal relationships among the radiographic parameters and other soft tissue parameters that may play a role, since magnetic resonance images were not available for the cohort. Fourth, in this study, there was no ethnic record and the cervical radiograph was obtained from a single hospital; in fact, the effect of ethnicity on the sagittal alignments of the cervical spine should be taken into consideration to determine if our results are globally generalizable [22]. Fifth, the number of subjects aged over 70 years was small, the results in the older population may be less accurate than those of the younger age groups. Last but not least, this study did not include lateral radiographs of the full body or of the full trunk, and the relationship between cervical lordosis and other global sagittal parameters, such as thoracolumbar alignments and knee flexion angle, could therefore not to be discussed [2, 3, 14]. The upper and lower cervical spine was anatomically complex, and various factors may affect the lordotic curve of cervical spine. As such, prospective multicentre investigations are further needed to account for other factors to extend our results, such as genetic predisposition [23], history of cervical trauma [24] or the condition of posterior neck muscles [25].

Despite these limitations, we believe that results from our large-scale study will improve the understanding of the importance of these factors in determining the cervical lordosis, and findings would serve as references for future investigations involving the cervical lordotic curvature.

\section{Conclusion}

The current study described the relative influence of age, sex, the extent of disc height loss and T1 slope on cervical lordosis. We found that $\mathrm{T} 1$ slope had the greatest influence on $\mathrm{C} 2-\mathrm{C} 7$ lordosis among the common variables studied in our study. Additionally, age, sex and disc height loss were not independently associated with upper cervical lordosis. 
Funding Open Access funding enabled and organized by Projekt DEAL.

\section{Declaration}

Conflict of interest The authors of this study declare that they have no conflict of interest to disclose.

Open Access This article is licensed under a Creative Commons Attribution 4.0 International License, which permits use, sharing, adaptation, distribution and reproduction in any medium or format, as long as you give appropriate credit to the original author(s) and the source, provide a link to the Creative Commons licence, and indicate if changes were made. The images or other third party material in this article are included in the article's Creative Commons licence, unless indicated otherwise in a credit line to the material. If material is not included in the article's Creative Commons licence and your intended use is not permitted by statutory regulation or exceeds the permitted use, you will need to obtain permission directly from the copyright holder. To view a copy of this licence, visit http://creativecommons.org/licenses/by/4.0/.

\section{References}

1. Ames CP, Blondel B, Scheer JK, Schwab FJ, Le Huec JC, Massicotte EM, Patel AA, Traynelis VC, Kim HJ, Shaffrey CI, Smith JS, Lafage V (2013) Cervical radiographical alignment: comprehensive assessment techniques and potential importance in cervical myelopathy. Spine Phila Pa 1976 38(22):S149-S160. https://doi. org/10.1097/BRS.0b013e3182a7f449

2. Barrey C, Roussouly P, Le Huec JC, D’Acunzi G, Perrin G (2013) Compensatory mechanisms contributing to keep the sagittal balance of the spine. Eur Spine J 22(S6):834-841. https://doi.org/10. 1007/s00586-013-3030-z

3. Iyer S, Lenke LG, Nemani VM, Fu M, Shifflett GD, Albert TJ, Sides BA, Metz LN, Cunningham ME, Kim HJ (2016) Variations in occipitocervical and cervicothoracic alignment parameters based on age: a prospective study of asymptomatic volunteers using full-body radiographs. Spine Phila Pa 1976 41(23):18371844. https://doi.org/10.1097/BRS.0000000000001644

4. Zhou S, Xu F, Wang W, Zou D, Sun Z, Li W (2020) Age-based normal sagittal alignment in Chinese asymptomatic adults: establishment of the relationships between pelvic incidence and other parameters. Eur Spine J 29(3):396-404. https://doi.org/10.1007/ s00586-019-06178-9

5. Guo GM, Li J, Diao QX, Zhu TH, Song ZX, Guo YY, Gao YZ (2018) Cervical lordosis in asymptomatic individuals: a metaanalysis. J Orthop Surg Res 13(1):147. https://doi.org/10.1186/ s13018-018-0854-6

6. Tao Y, Galbusera F, Niemeyer F, Samartzis D, Vogele D, Wilke HJ (2021) Radiographic cervical spine degenerative findings: a study on a large population from age 18 to 97 years. Eur Spine J 30(2):431-443. https://doi.org/10.1007/s00586-020-06615-0

7. Gore DR, Sepic SB, Gardner GM (1986) Roentgenographic findings of the cervical spine in asymptomatic people. Spine Phila $\mathrm{Pa} 1976$ 11(6):521-524. https://doi.org/10.1097/00007632-19860 7000-00003

8. Harada GK, Tao Y, Louie PK, Basques BA, Galbusera F, Niemeyer F, Wilke HJ, Goldberg E, An HS, Samartzis D (2021) Cervical spine MRI phenotypes and prediction of pain, disability and adjacent segment degeneration/disease after ACDF. J Orthop Res 39(3):657-670. https://doi.org/10.1002/jor.24658

9. Ferrara LA (2012) The biomechanics of cervical spondylosis. Adv Orthop 2012:493605. https://doi.org/10.1155/2012/493605
10. Yukawa Y, Kato F, Suda K, Yamagata M, Ueta T (2012) Agerelated changes in osseous anatomy, alignment, and range of motion of the cervical spine. Part I: radiographic data from over 1200 asymptomatic subjects. Eur Spine J 21(8):1492-1498. https://doi.org/10.1007/s00586-012-2167-5

11. Lee SH, Son ES, Seo EM, Suk KS, Kim KT (2015) Factors determining cervical spine sagittal balance in asymptomatic adults: correlation with spinopelvic balance and thoracic inlet alignment. Spine J 15(4):705-712. https://doi.org/10.1016/j.spinee.2013.06. 059

12. Been E, Shefi S, Soudack M (2017) Cervical lordosis: the effect of age and gender. Spine J 17(6):880-888. https://doi.org/10.1016/j. spinee.2017.02.007

13. Lafage R, Challier V, Liabaud B, Vira S, Ferrero E, Diebo BG, Liu S, Vital JM, Mazda K, Protopsaltis TS, Errico TJ, Schwab FJ, Lafage V (2016) Natural head posture in the setting of sagittal spinal deformity: validation of chin-brow vertical angle, slope of line of sight, and McGregor's slope with health-related quality of life. Neurosurgery 79(1):108-115. https://doi.org/10.1227/NEU. 0000000000001193

14. Theologis AA, Iyer S, Lenke LG, Sides BA, Kim HJ, Kelly MP (2019) Cervical and cervicothoracic sagittal alignment according to Roussouly thoracolumbar subtypes. Spine Phila Pa 1976 44(11):E634-E639. https://doi.org/10.1097/BRS.0000000000 002941

15. Harrison DE, Harrison DD, Cailliet R, Troyanovich SJ, Janik TJ, Holland B (2000) Cobb method or Harrison posterior tangent method: which to choose for lateral cervical radiographic analysis. Spine Phila Pa 1976 25(16):2072-2078. https://doi.org/10.1097/ 00007632-200008150-00011

16. Kettler A, Rohlmann F, Neidlinger-Wilke C, Werner K, Claes L, Wilke HJ (2006) Validity and interobserver agreement of a new radiographic grading system for intervertebral disc degeneration: part II cervical spine. Eur Spine J 15(6):732-741. https://doi.org/ 10.1007/s00586-005-1037-9

17. Landis JR, Koch GG (1977) The measurement of observer agreement for categorical data. Biometrics 33(1):159-174

18. Schober P, Boer C, Schwarte LA (2018) Correlation coefficients: appropriate use and interpretation. Anesth Analg 126(5):17631768. https://doi.org/10.1213/ANE.0000000000002864

19. Yokoyama K, Kawanishi M, Yamada M, Tanaka H, Ito Y, Kawabata S, Kuroiwa T (2017) Age-related variations in global spinal alignment and sagittal balance in asymptomatic Japanese adults. Neurol Res 39(5):414-418. https://doi.org/10.1080/01616412. 2017.1296654

20. Goh S, Tan C, Price RI, Edmondston SJ, Song S, Davis S, Singer KP (2000) Influence of age and gender on thoracic vertebral body shape and disc degeneration: an MR investigation of 169 cases. J Anat 197(Pt 4):647-657. https://doi.org/10.1046/j.1469-7580. 2000.19740647.x

21. Liu B, Wu B, Van Hoof T, Okito JP, Liu Z, Zeng Z (2015) Are the standard parameters of cervical spine alignment and range of motion related to age, sex, and cervical disc degeneration? J Neurosurg Spine 23(3):274-279. https://doi.org/10.3171/2015.1. SPINE14489

22. Ames C, Gammal I, Matsumoto M, Hosogane N, Smith JS, Protopsaltis T, Yamato Y, Matsuyama Y, Taneichi H, Lafage R, Ferrero E, Schwab FJ, Lafage V (2016) Geographic and ethnic variations in radiographic disability thresholds: analysis of North American and Japanese operative adult spinal deformity populations. Neurosurgery 78(6):793-801. https://doi.org/10.1227/NEU. 0000000000001184

23. Stone MA, Osei-Bordom DC, Inman RD, Sammon C, Wolber LE, Williams FM (2015) Heritability of spinal curvature and its relationship to disc degeneration and bone mineral density in female 
adult twins. Eur Spine J 24(11):2387-2394. https://doi.org/10. 1007/s00586-014-3477-6

24. Marshall DL, Tuchin PJ (1996) Correlation of cervical lordosis measurement with incidence of motor vehicle accidents. Australas Chiropr Osteopathy 5(3):79-85

25. Tamai K, Grisdela P Jr, Romanu J, Paholpak P, Nakamura H, Wang JC, Buser Z (2019) The impact of cervical spinal muscle degeneration on cervical sagittal balance and spinal degenerative disorders. Clin Spine Surg 32(4):E206-E213. https://doi.org/10. 1097/BSD.0000000000000789

Publisher's Note Springer Nature remains neutral with regard to jurisdictional claims in published maps and institutional affiliations. 